\title{
Post-exposure Rabies Prophylaxis for Children in Southern Turkey
}

\author{
Can Celiloglu, Ulas Özdemir, Orkun Tolunay, Asena Sucu and Umit Celik \\ Department of Pediatrics, University of Medical Sciences, Adana City Training and Research Hospital, Adana, Turkey
}

\begin{abstract}
Objective: To evaluate the prophylaxis practices used on children with animal exposures in a major southern city of Turkey, close to the Syrian border.

Study Design: Cross-sectional study.

Place and Duration of Study: Emergency and Outpatient departments, Adana City Training and Research Hospital, Turkey between September 2017 and September 2018.

Methodology: The demographic data of the patients, who presented due to animal contact; the interval between animal contact and hospital presentation; species of exposed animals, type, and apparent condition of the animals; risk categories based on national assessment scale; the number of rabies vaccines and anti-rabies immunoglobulin (RIG) administrations; administration of tetanus prophylaxis; adherence of patients to the follow-up schedule; vaccine refusals; and development of rabies disease (if any), were recorded.

Results: Of the 2,068 presentations after animal exposure, $906(43.8 \%)$ were children, mostly boys $(62 \%)$, and the mean age was $97.15 \pm 57.68$ months. Risky contact was most frequently caused by cats $(52.8 \%)$ and dogs $(45.6 \%)$. Exposure to stray animals was the most common (58.5\%). For serial prophylaxis vaccinations, $761(83.99 \%)$ families were in full compliance and $145(16 \%)$ families had discontinued vaccinations. The discontinuation rate of the immigrant population was significantly higher $(p=0.001)$.

Conclusion: Risky contacts were mostly due to stray animals. Efforts to minimise the stray animal population should be increased. The rate of discontinuation of rabies prophylaxis follow-ups was $16 \%$. Significantly higher prophylaxis discontinuation among the immigrant population was noted.
\end{abstract}

Key Words: Rabies, Vaccines, Prophylaxis, Turkey.

How to cite this article: Celiloglu C, Özdemir U, Tolunay O, Sucu A, Celik U. Post-exposure Rabies Prophylaxis for Children in Southern Turkey. J Coll Physicians Surg Pak 2021; 31(10):1219-1223.

\section{INTRODUCTION}

Rabies is an acute, rapidly progressive encephalitis, and is one of the oldest known zoonotic diseases. The causative agent is the rabies virus, which is an enveloped, single-stranded RNA virus from the rhabdoviridae family under the genus of lyssavirus. ${ }^{1}$ Despite medical developments, rabies almost invariably progresses to death. ${ }^{2}$ Rabies continues to be a serious public health problem due to the high mortality rate; and medical care costs of post-exposure prophylaxis practices. ${ }^{3}$ It is estimated that around 59,000 people die of rabies each year worldwide. ${ }^{4}$ According to data of the World Health Organization (WHO), around 15 million post-exposure prophylaxis applications are performed worldwide, annually. ${ }^{5}$

Correspondence to: Dr. Can Celiloğlu, Department of Pediatrics, University of Medical Sciences, Adana City Training and Research Hospital, Adana, Turkey

E-mail: canceliloglu@yahoo.com

Received: February 13, 2020; Revised: March 06, 2021;

Accepted: March 30, 2021

DOI: https://doi.org/10.29271/jcpsp.2021.10.1219
Dogs are the most important reservoir for rabies virus, and dog bites account for up to $99 \%$ of human rabies cases. ${ }^{6}$ Turkey remains an endemic country in terms of rabies. ${ }^{7}$ Approximately 180,000 rabies risk-posing animal contacts are reported; and 1-2 human rabies cases are seen annually in Turkey. ${ }^{7}$ Turkey is unique in that it is the only European country in which the principal vector for rabies is the domestic dog (canis familiaris), rather than the fox (vulpes vulpes). ${ }^{8}$ The stray animal population is a major concern in Turkey. Municipalities are responsible for the treatment of stray animals in Turkey. According to current law, animals are vaccinated, kept temporarily in shelters, and released into nature. There are no data on the total number of stray animals and the vaccinated percentage of these animals.

It is well known that no cases of documented rabies develop when strict adherence to post-exposure prophylaxis rules is established. ${ }^{5}$ A comprehensive field prophylaxis programme is ongoing within Turkey's health system, because rabies disease is lethal and a potentially preventable health problem. The rabies vaccine prophylaxis cost is funded by the Government Health System. The vaccine type used in Turkey is "purified vero 
cell vaccine." However, despitethe efforts of the health administration on rabies prophylaxis measures, both the enormous immigrant flow that occurred from Syria and the emerging vaccine hesitancy among different socioeconomic levels of the population poses new challenges to Turkey's health system. The rate of adherence of families to rabies post-exposure prophylaxis measures is of importance. $^{9}$

The aim of the present study was to investigate the total number of admittance to our hospital for post-exposure rabies prophylaxis between September 2017 and September 2018, the rate of pediatric cases among all hospital presentations, the species of animals and types of human exposure, the number of developed rabies diseases if any, and the rate of adherence of patients to the follow-up process among Turkish and immigrant populations.

\section{METHODOLOGY}

The study was conducted in Adana City Training and Research Hospital, Turkey. Medical records of patients, who presented due to risky animal contacts between September 2017 and September 2018, were evaluated retrospectively, based on electronic records of the hospital. Patients aged under 18 years of all nationalities were included. Cases with record errors and missing data were excluded from the study (Figure 1). The demographic data of the patients; the interval between animal contact and hospital presentation; species of exposed animals, type of animal contacts, and apparent condition of the animals; risk categories based on the national assessment scale (Table I); the number of rabies vaccines and anti-rabies immunoglobulin (RIG) administrations, administration of tetanus prophylaxis, adherence of patients to follow-up schedules; vaccine refusals; and development of rabies disease (if any) were recorded.

(1) If the exposed animal presents any kind of rabies symptoms, dies or escapes, then rabies vaccination is to be commenced.

(2) If the exposed animal presents any kind of rabies symptoms or dies; rabies vaccination should be commenced anti-rabies Ig should beadministered.

(3) If the exposed animal (dog or cat) is healthy for 10 days after the incident, vaccination should be stopped.

(4) If the exposed animal (dog orcat) presents any kind of rabies symptoms, dies or escapes, anti-rabies Ig should be administered within 7 days following the first dose of rabies vaccination. If more than 7 days have passed, anti-rabies Ig should not be administered instead; 5 th dose of rabies vaccination should be added to the scheme.

(5) If anti-rabies Ig is not immediately available, it should be administered within the following 7 days.

The statistical analysis was performed using the Statistical Package for Social Sciences version 20 (IBM Corp., Armonk, NY, USA) software package. The Kolmogorov-Smirnov test was used to evaluate whether the numeric variables of the study group met the assumption of normal distribution. Descriptive statistics of the numerical parametric variables were calculated as mean \pm standard deviation; non-parametric variables were calculated in the median and interquartile range (IQR) and categorical variables were given as a percentage (\%). A Chi-square test was performed for the comparison of categorical variables between groups. A p value of $<0.05$ was considered statistically significant.

Ethical approval regarding the study was obtained from the Adana City Education and Research Hospital Clinical Research Ethics Committee (Meeting No. 26; Date 05.02.2018; Decision number: 350 .

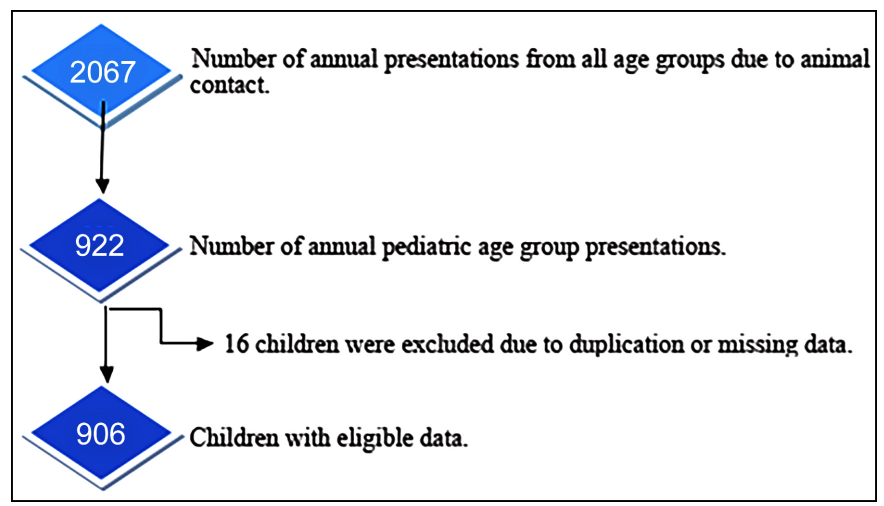

Figure 1: Flow diagram of the study group.

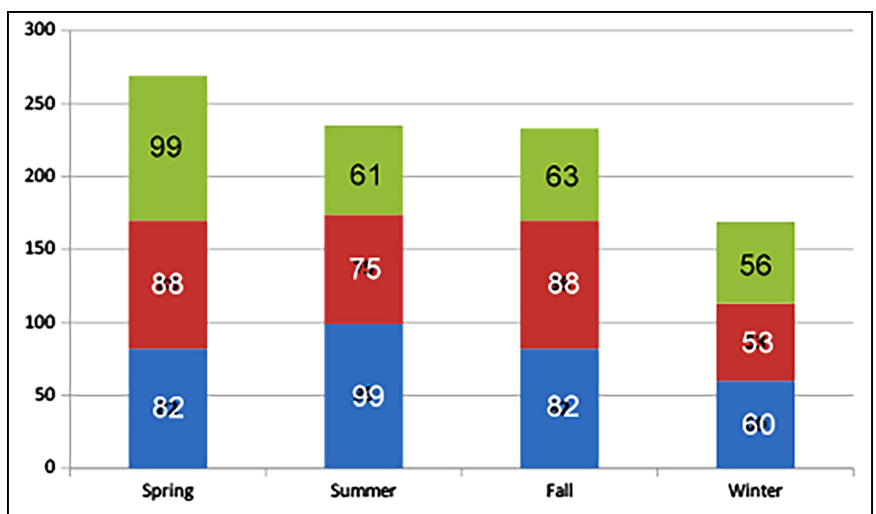

Figure 2: Seasonal and monthly distribution of hospital presentations due to animal contacts with suspicion of rabies.

\section{RESULTS}

Within one year from September 2017 to September 2018, 906 children were enrolled in the study (Table II). The median age of the children was 91 months (47-142.2). The day of presentation was termed as day 0 , if presentation occurred $<24$ hours after the animal contact. Seven hundred and twenty $(79.4 \%)$ of the children presented to our clinic within 24 hours, and the latest presentation was 12 days after the contact. The mean interval between animal contact and hospital admission was $0.41 \pm$ 1.15 days.

When the cases were aligned, according to the months of hospital presentation, the lowest number of presentations were in January $(n=53,5.8 \%)$ and February $(n=56,6.2 \%)$; and the highest numbers of presentations were in May $(n=99,10.9 \%)$ and June ( $n=99,10.9 \%)$ (Figure 2 ). 
Table I: Risk categories of animal exposures according to the T.R. Ministry of Health, National Rabies Field Guide.

\begin{tabular}{|c|c|c|c|c|}
\hline 1 & \multicolumn{3}{|l|}{$\begin{array}{l}\text {-Touching/feeding the animal } \\
\text {-Intact skin exposure to animal's saliva }\end{array}$} & No intervention warranted \\
\hline \multirow{3}{*}{2} & \multirow{3}{*}{$\begin{array}{l}\text {-Slight scratching of skin (injuries not } \\
\text { extending to subcutaneous tissue) } \\
\text {-Minor injuries without bleeding }\end{array}$} & \multicolumn{2}{|c|}{ If the exposed animal was vaccinated within the last year } & $\begin{array}{l}\text { Wound care } \\
\text { Evaluation for tetanus prophylaxis } \\
\text { Observation of animal for } 10 \text { days }^{1}\end{array}$ \\
\hline & & \multirow{2}{*}{$\begin{array}{l}\text { If the exposed animal was not } \\
\text { vaccinated within the last year } \\
\text { or vaccination status is } \\
\text { unknown }\end{array}$} & $\begin{array}{l}\text { If the animal is healthy } \\
\text { and can be observed } \\
\text { properly }\end{array}$ & $\begin{array}{l}\text { Wound care } \\
\text { Evaluation for tetanus prophylaxis } \\
\text { Observation of animal for } 10 \text { days }^{1}\end{array}$ \\
\hline & & & $\begin{array}{l}\text { If the animal cannot be } \\
\text { observed }\end{array}$ & $\begin{array}{l}\text { Wound care } \\
\text { Evaluation for tetanus prophylaxis } \\
\text { Initiation of rabies vaccination }\end{array}$ \\
\hline \multirow{3}{*}{3} & \multirow{3}{*}{$\begin{array}{l}\text {-Bites/scratches penetrating the skin } \\
\text {-Exposure of open wounds/mucosa to } \\
\text { animal's saliva } \\
\text {-Lesions localised to head, fingertips } \\
\text { (areas of dense innervation) }\end{array}$} & \multicolumn{2}{|c|}{ If the exposed animal was vaccinated within the last year } & $\begin{array}{l}\text { Wound care } \\
\text { Evaluation for tetanus prophylaxis } \\
\text { Observation of animal for } 10 \text { days }^{2}\end{array}$ \\
\hline & & \multirow{2}{*}{$\begin{array}{l}\text { If the exposed animal was not } \\
\text { vaccinated within the last year } \\
\text { or vaccination status is } \\
\text { unknown }\end{array}$} & $\begin{array}{l}\text { If the animal is healthy } \\
\text { and can be observed } \\
\text { properly }\end{array}$ & $\begin{array}{l}\text { Wound care } \\
\text { Ovaluation for tetanus prophylaxis } \\
\text { Commencement of rabies vaccination } \\
\text { Observation of animal for } 10 \text { days }^{3} \\
\text { Administration of anti-rabies } \text { lg }^{4}\end{array}$ \\
\hline & & & $\begin{array}{l}\text { If the animal cannot be } \\
\text { observed }\end{array}$ & $\begin{array}{l}\text { Wound care } \\
\text { Ovaluation for tetanus prophylaxis } \\
\text { Commencement of rabies vaccination } \\
\text { Administration of anti-rabies } \mathrm{Ig}^{5}\end{array}$ \\
\hline 4 & \multicolumn{3}{|c|}{ Exposure to wild animals with a risk of rabies } & $\begin{array}{l}\text { Wound care } \\
\text { Ovaluation for tetanus prophylaxis } \\
\text { Commencement of rabies vaccination } \\
\text { Administration of anti-rabies } \mathrm{Ig}^{5}\end{array}$ \\
\hline
\end{tabular}

Table II: Demographic and clinical characteristics of the study group.

\begin{tabular}{|l|l|l|}
\hline Parameter & \multicolumn{2}{|l|}{ n (\%) } \\
\hline Age (median) & 91 months & $565(62.4 \%)$ \\
\hline \multirow{2}{*}{ Sex } & Male & $341(37.6 \%)$. \\
\hline \multirow{2}{*}{ Nationality } & Female & $876(96.7 \%)$ \\
& T.R. & $30(3.3 \%)$ \\
\hline \multirow{5}{*}{ The exposed animal species } & Immigrant & $478(52.8 \%)$ \\
& Cat & $413(45.6 \%)$ \\
& Dog & $4(0.4 \%)$ \\
& Bat & $11(1.2 \%)$ \\
\hline \multirow{5}{*}{ The type of animal contact } & Other species & $428(47.2 \%)$ \\
& Scratch & $388(42.8 \%)$ \\
& Bite & $11(1.2 \%)$ \\
& Open wound contact & $79(8.7 \%)$ \\
\hline & Other types of trauma & \\
\hline
\end{tabular}

The exposed animals were stray animals in 530 (58.5\%) cases that could not be observed after the contact. In 11 $(1.2 \%)$ cases, the animals were reported to be deceased. Only $94(25.7 \%)$ of 365 owned animals were reported to be vaccinated properly.

When post-exposure procedures were categorised according to the Rabies Field Guide of the T.C. Ministry of Health in 2014 (Table I), 19 (2.1\%) cases were classified as category I, 210 (23.2\%) were classified as category II, 673 $(74.2 \%)$ cases were classified as category III, and four $(0.4 \%)$ were classified as category IV.

Table III: Administration of rabies vaccine, rabies immunoglobulin
(RIG), and rates of compliance of families with follow-up.

\begin{tabular}{|l|l|}
\hline Number of administered rabies vaccine & \\
No vaccine administered & $22(2.4 \%)$ \\
1 dose & $95(10.4 \%)$ \\
2 doses & $51(5.6 \%)$ \\
3 doses & $108(11.9 \%)$ \\
4 doses & $526(58 \%)$ \\
5 doses & $104(11.4 \%)$ \\
\hline RIG administration & \\
Administered & $447(49.3 \%)$ \\
Not administered & $459(50.7 \%)$ \\
\hline Prior full dose anti-rabies vaccination within a year & \\
Administered & $11(1.2 \%)$ \\
Not administered & $895(98.8 \%)$ \\
\hline Compliance of families with follow-up & \\
Full compliance & $761(84 \%)$ \\
Discontinuation & $122(13.5 \%)$ \\
Vaccine refusal & $23(2.5 \%)$ \\
\hline Compliance of Prophylaxis Applications to National Guideline & \\
Full compliance & $716(79.1 \%)$ \\
Inappropriate & $190(20.9 \%$ \\
\hline
\end{tabular}

Besides local wound care and animal observation, for 22 children $(2.4 \%)$, no procedures were performed, intramuscular (im) RIG and a 4-dose scheme of rabies vaccinations were performed for 456 (50.3\%) children, a 4-dose scheme of rabies vaccinations was performed for $224(24.7 \%)$ children, and a 5-dose scheme of rabies vaccinations (0.3.7.14, 28 days) was planned for post-exposure prophylaxis for 204 $(22.5 \%)$ children (Table III). The mean number of rabies vaccines administered per child was $3.54 \pm 1.17$.

When evaluated according to the Rabies Field Guideline, anti- 
rabies post-exposure prophylaxis practices were properly performed in $716(79 \%)$ children. Non-compliance with the guidelines was found in 190 (21\%) cases. When the factors of the non-compliance were examined, parents of $122(13.5 \%)$ children discontinued the follow-ups without declaring any reason, the parents of $23(2.5 \%)$ children signed that they refused for their child to be vaccinated, and in 45 cases, other types of non-compliance with the guideline were observed. The mean age of patients, who discontinued prophylaxis follow-up and those who were continuing follow-up, were compared and no significant difference was found.

When compared in terms of the rate of discontinuation of rabies prophylaxis vaccination follow-ups, this rate was higher in immigrant patients (15.3\% vs. 36.7\%). Fortunately, no human rabies case was observed in the region of the authors during the one year within the scope of the present study.

\section{DISCUSSION}

Prophylaxis after risky contact is of great importance during the struggle against rabies ${ }^{2}$. In the current literature, 41.9-49.6\% of all patients, who present to hospitals for rabies prophylaxis after animal contact, are children and this study results are consistent with the literature. ${ }^{10,11}$ Males presented more frequently with rabies-risk contacts, which is consistent with the literature. ${ }^{10-12}$ In the literature, animal contacts evaluated for rabies prophylaxis have been reported to increase during school holiday periods. ${ }^{13}$ In this study, the most frequent presentations were in May and June. The increase in presentations during these warm months may be attributed to the increased time spent in outdoor areas, thus raising the possibility of exposure to animals.

In this study, the most common species of exposed animals were found as cats and dogs, respectively. In the literature, the leading species that caused post-exposure rabies prophylaxis was reported as dogs. ${ }^{10,12,14}$ In most studies, it was reported that stray dogs were the most common cause of post-exposure rabies prophylaxis presentations. ${ }^{12,15}$ In this study, $58.5 \%$ of the animals were stray animals. We found cats as the most frequently exposed animals and these data were not consistent with the literature, but consistent with another study conducted in Turkey. ${ }^{16}$

When post-exposure prophylaxis against rabies studies are examined, the most frequently reported risk categories were as follows: category II in Poland, ${ }^{14}$ category I in India, ${ }^{15}$ and category III in Greece ${ }^{12}$ and Turkey. ${ }^{16}$ Risk category III was found here as the leading risk level and this result is in agreement with the literature.

In terms of post-exposure prophylaxis against rabies, serious insufficiencies have been reported, especially in developing countries. In a study conducted in Brazil, it was reported that $95.8 \%$ of patients, who presented with risky contact, were under-treated. ${ }^{3}$ In this analysis, $79 \%$ of post-exposure prophylaxis was performed in accordance with the guidelines structured for Turkey. Turkey's ongoing health policies include completely unrestricted, free-of-charge emergency health services, regardless of nationality or insurance coverage, and this may play a role in this relatively successful rate of proper prophylaxis compared with the other developing countries.

Studies have shown that compliance of the population with the post-exposure rabies follow-ups may be low in developing countries. In a study from the Ivory Coast, the rate of discontinuation of follow-ups was reported as $52.7 \%$, it was $22.6 \%$ in Thailand. ${ }^{17,18}$ In this study, the follow-up rate was lower (16\%) than those. However, studies from Turkey and Europe with vaccine doses administered at $100 \%$ and no discontinuation during follow-ups have also been reported in the literature. ${ }^{14,16}$ This high dropout rate in this study may be due to the high rate of rural presentations with a low economic-educational level and a high number of presentations from the immigrant population (almost all from Syria). ${ }^{19}$ Increasing knowledge levels of both local and refugee families regarding the importance of rabies vaccination may increase the compliance rates with the rabies vaccination scheme.

The progress made by some developed countries regarding rabies is inspiring. In Singapore, for instance, rabies has not been seen since 1953. In Turkey, 1-2 rabies cases are seen annually. In this study, we observed that the animals causing rabies-risk contact were predominantly stray. Reducing the stray animal population by preventing further abandonment of animals to the streets may lower the risk of rabies posing through animal contact with children. ${ }^{20}$

The retrospective nature of this study is one of the major limitations. Although the time between contact and presentation has been reported as hours in some publications, the authors could not obtain these data, thus reported this interval in days. The authors even could not obtain data about the level of education of the parents, monthly income or language/financial/geographic difficulties causing difficulties in accessing hospitals for vaccinations. In the present study, it was not possible to question the extent to which the immigrant population gained information about rabies and the importance of prophylaxis vaccinations. In the forthcoming studies, it may be examined whether the high dropout rate of these families of foreign nationalities is due to lack of information about rabies and the importance of serial vaccinations.

\section{CONCLUSION}

A higher proportion of discontinuation of post-exposure prophylaxis vaccinations was observed among the immigrant population; and efforts to raise the awareness about rabies and prophylaxis practices of this disadvantaged population should be increased. This study emphasised the importance of developing administrative mechanisms to reduce the number of stray animals and increase compliance with post-exposure prophylaxis. 


\section{ETHICAL APPROVAL:}

This study was approved by the Clinical Research Ethics Committee of the Adana City Training and Research Hospital (Meeting No. 26; Date 05.02.2018; Decision No. 350) prior to the initiation of the research.

\section{PATIENTS' CONSENT:}

Informed consents were not obtained from patients due to the retrospective nature of the study.

\section{CONFLICT OF INTEREST:}

The authors declared no conflict of interest.

\section{AUTHORS' CONTRIBUTION:}

CC: Design of the study.

CC, UÖ, AS: Data acquisition.

OT, ÜÇ: Substantial contributions to the conception and design of the work.

CC, OT, ÜÇ: Final approval of the version to be published and revising it critically for important intellectual content.

\section{REFERENCES}

1. Willoughby RE. Rabies. In: Kliegman R, Stanton B, St. Geme JW, Schor NF, Behrman RE, Eds. Nelson Textbook of Pediatrics. Ed. 20th, Philadelphia; Elsevier; 2016: p. 1641-3.

2. American Academy of Pediatrics. Kimberlin DW, Brady MT, Jackson MA, Long SS, editors. Red Book: 2015 Report of the Committee on Infectious Diseases. ed. $30^{\text {th }}$, Elk Grove Village; American Academy of Pediatrics; 2015.

3. Cavalcante KKS, Alencar $\mathrm{CH}$. Human rabies: Evaluation of post-exposure prophylaxis prevalence in Ceará, Brazil. Epidemiol Serv Saude 2018; 29(4):e2017547. doi:10. 5123/S1679-49742018000400009.

4. WHO. WHO expert consultation on rabies. Geneva: WHO technical report series; 2018. http://apps.who.int/iris/bitstream/handle/10665/272364/978 9241210218-eng.pdf?ua=1 (Accessed on 2/22/2021).

5. 5-WHO. Rabies: World health organization; 2019. http://www.who.int/news-room/fact-sheets/detail/rabies (Accessed on 2/22/2021).

6. Fooks AR, Cliquet F, Finke S, Freuling C, Hemachudha T, Mani RS, et al. Rabies. Nat Rev Dis Primers 2017; 3:1-19. doi:10. 1038/nrdp.2017.91.

7. T.R. Ministry of health. Kuduz Saha Rehberi Ankara: T.C. Sağlık bZakanlığı; 2014. Available from: http://dosyaism.saglik.gov.tr/Eklenti/21615,kuduz-saha-rehbe ripdf.pdf?0 [cited 10/1/2020].

8. Johnson N, Un H, Vos A, Aylan O, Fooks AR. Wildlife rabies in Western Turkey: The spread of rabies through the western provinces of Turkey. Epidemiol Infect 2006; 134(2):369-75. doi: 10.1017/S0950268805005017.

9. Bozkurt HB. An overview of vaccine rejection and review of literature. Kafkas J Med Sci 2018; 8:71-6. doi: 10.5505/kjms.2018.12754.

10. De Paula NS, Saraiva EA, Araújo IM, Nascimento KKG, Xavier DA, Santos KS, et al. Characterisation of rabies post-exposure prophylaxis in a region of the eastern Amazon, state of Pará, Brazil, between 2000 and 2014. Zoonoses Public Health 2018; 65(4):395-403. doi: 10.1111/zph

11. Karadaş MA, Yılmaz F, Demir TA, Okudan RN, Çalışkan G. Evaluation of animal contacted patients with rabies suspected. Exposures presented to antalya training and research hospital emergency service. Acta Medica Alanya 2018; 2:163-9. doi: 10.30565/medalanya.413956.

12. Dougas G, Konte V, Mitrou K, Georgakopoulou T, Baka A, Liona $A$, et al. Surveillance of rabies postexposure prophylaxis in greece: 4 Years' Experience. Vector Borne Zoonotic Dis 2019; 19(4):295-301. doi: 10.1089/vbz.2018.2344.

13. Kularatne SA, Ralapanawa DM, Weerakoon K, Bokalamulla UK, Abagaspitiya N. Pattern of animal bites and post exposure prophylaxis in rabies: A five-year study in a tertiary care unit in Sri Lanka. BMC Infect Dis 2016; 16:62. doi: 10.1186/s12879-016-1394-5.

14. Krzowska-Firych J, Tomasiewicz K, Kozøowska A. Post-exposure rabies prophylaxis in humans exposed to animals in lublin province (Eastern Poland) in 2012-2015 - A retrospective study. Hum Vaccin Immunother 2017; 13(6):1346-51. doi.org/10.1080/21645515.2017.1285474.

15. Samanta M, Mondal R, Shah A, Hazra A, Ray S, Dhar G, et al. Animal bites and rabies prophylaxis in rural children: Indian perspective. J Trop Pediatr 2016; 62(1):55-62. doi: 10.1093/ tropej/fmv072.

16. Aldemir-Kocabaş B. Retrospective assessment of children exposed to animals and the anti-rabies prophylaxis practices in our clinic. Turkish J Pediatr Dis 2018; 2:104-7. doi: 10.12956/tjpd.2017.297.

17. Tiembre I, Benie J, Attoh-Touré H, Zengbe-Acray P, Tetchi SM, Kpebo D, et al. Discontinuation of postexposure prophylaxis at the anti-rabies Center of Abidjan, Côte d'Ivoire. Bull Soc Pathol Exot 2013; 106(4):272-7. doi: 10.1007/s13149-013 $-0312-y$.

18. Tepsumethanon S, Tepsumethanon V, Tantawichien T, Suwansrinon $\mathrm{K}$, Wilde $\mathrm{H}$, et al. Problems in human rabies post-exposure prophylaxis management. Travel Med Infect Dis 2007; 5(3):189-93. doi:10.1016/j.tmaid.2006.07.001

19. Diamond M, Oberg C. Gender-related challenges in educational interventions with syrian refugee parents of trauma-affected children in Turkey. Children (Basel) 2019; 6(10): 110.

20. Kasempimolporn S, Jitapunkul S, Sitprija V. Moving towards the elimination of rabies in Thailand. J Med Assoc Thai 2008; 91(3): 433-7. 